\title{
Does Organisational Socialisation Resembles Employee Orientation? Or is There More to It? (A Comprehensive Review of Literature)
}

\author{
H.M. Nishanthi \\ Department of Human Resource Management \\ Faculty of Commerce and Management Studies, University of Kelaniya \\ Kelaniya, Sri Lanka \\ E-mail:menaka@kln.ac.lk
}

Received: July 17, 2017 Accepted: August 7, 2017 Online published: September 22, 2017 doi:10.5296/ijhrs.v7i4.11557

URL: https://doi.org/10.5296/ijhrs.v7i4.11557

\begin{abstract}
The concept of organisational socialisation has been widely tested in the international context as well as in local context with the view that it is a process where novel candidates are familiarised to the current organisational setting. Hence, it is viewed as an orienting programme. However, it is worthwhile to examine whether the process of organisational socialisation is a mere employee orienting programme or whether there is more to it than this. This viewpoint is assessed below through a comprehensive literature review.
\end{abstract}

Keywords: Organisational Socialisation, Employee Orientation

\section{What is Organisational Socialisation?}

According to Bauer, Bodner, Erdogan, Truxillo, and Tucker (2007) organisational socialisation is identified as the procedure where novel employees are transformed to be a member of the organisation from being a stranger. Van Maanen and Schein (1979) identify organizational socialisation as a conversion procedure where organisational members structure how employees' experiences are transferred from one role to another. Louis (1980, p. 229 as cited in Taormina, 2009) defined organisational socialisation as "the process by which an individual comes to appreciate the values, abilities, expected behaviours, and social knowledge essential for assuming an organisational role and for participating as an organisational member". Van Maanen $(1979$, p. 19) refers organisational socialisation to the "manner in which experiences of people learning the ropes of a new organisational position, status, or role are structured for them by others within the organisation". According to 
Reichers (1987), organisational socialisation is identified as a procedure where organisation has the option of recruiting or terminating an employee, however, employees also have the option of adapting to the work setting of the organisation or not to whereby they will leave the organisation. The best situation is where the both parties would display cooperation among them enabling the organsational socialisation to be a two-way process. Further, Taormina (1994, p. 133) defined organisational socialisation as the "mechanism through which new employees acquire the necessary knowledge, skills, responsibility, and behaviours to obtain insiders' support and become effective organisational members". The meanings of this notion emphasis the value of socialisation which enable individuals to change their behavior patterns according to peers and the culture of the organisation (Taormina, 2009).

This concept can be viewed and categorised into sub components based on the empirical works of different prominent researchers such as Chao, O'Leary-Kelly, Wolf, Klein, and Gardner (1994), Feldman (1989), Louis (1980), Reichers (1987), and Van Maanen and Schein (1979). Of the highly recognized theoretical models on organisational socialisation, the model developed by Van Maanen and Schein's (1979), which is known as typology of organisational socialisation tactics is given greater priority when reviewing literature (Ashforth \& Saks, 1997). Van Maanen and Schein (1979) proposed six strategies that organisations are capable to adopt in structuring the socialisation activities particularly of novices to organisations. The collective versus individual tactics, formal versus informal tactics, sequential versus random tactics, fixed versus variable socialisation tactics and serial versus disjunctive tactics continuums were identified in their typology on employee socialisation (Filstad, 2011). Furthermore, Jones (1986 as cited in Filstad, 2011) developed a six 5-item scale to measure socialisation tactics based on Van Maanen and Schein (1979)'s strategies by separating the vertical socialisation strategies into three flat dimensions as social tactics (serial and investiture), content tactics (fixed and sequential) and context tactics formal and collective).

But Jones's (1986) scale was with weaknesses when used in socialisation research. There were issues regarding the reliability of the questions used for some of the factors. Even some factors were different across different research studies (Allen \& Meyer, 1990b; Jones, 1986). Marking their contribution to the socialisation literature, Chao et al. (1994) also created a model to quantify the level of socialisation depending upon previous literature on organisational socialisation. The principal sources related to their dimensions are articles by Feldman's (1981) classic review. The six dimensions were: (1) performance proficiency, which recognise the talent to execute a given duty; (2) goals and values, which associates to identifying and understanding the importance of the organisation's objectives (3) history, which relates to the education on organisation's stories, customs and rituals; (4) language, which associates to learning organisation specific jargon and/or technical language; (5) politics, that associates with understanding how to manage one's self within the organisation's authority influence; and (6) people, which relates to building and maintaining connections with peers and subordinates (Taormina, 2004). Likewise, Taormina (1994) has also revealed distinct content areas of socialisation where four dimensions of socialisation were explained, namely, training, understanding, co-worker support, and future prospects. 
Three dimensions of this conceptual model includes all six regions of socialisation considered by Chao et al. (1994), and added a fourth dimension, i.e. future prospects. Hence, these four arenas have been deliberated to be indicators of effective socialisation (Taormina, 1997).

\section{Organisational Socialisation by Taormina (1994)}

As mentioned above, Taormina (1994) identified four factors which are called domains, 'a sphere of influence or activity' (as cited in Taormina, 1997, p. 30) to measure employees' organisational socialisation. This model has been developed independently by Taormina (1994), based on the organisational socialisation literature. He further mentioned that these dimensions are parts of the continuous process organisational socialisation model, enabling to organise and group different variables discussed in organisational socialisation literature in to one model. Also it is expected that these for domains to work interchangeably with each other in developing socialisation of employees. The organisational socialisation index (OSI) which was developed based on this model comprises twenty (20) items in four dimensions (each comprising five questions).

Previous researchers on organisational socialisation (e.g. Feldman, 1981; Schein, 1978; Van Maanen, 1976) described this concept as involving a specific array of events. Though some scholars have viewed this as an endless process (e.g. Feldman, 1989; Van Maanen \& Schein 1979), the earlier mentioned misunderstanding has led to understand that organisational socialisation process is composed of distinct steps (Taormina, 1997). But, Taormina (1994)'s model has distinctively identified organisational socialisation as a continuous process where some activities tend to continue for long periods of time while some tend to appear simultaneously. Also some activities which were prevalent earlier might diminish in value and re-appear in a later day. This is the way the organizational socialisation process have been viewed.

Further, this model acquired the theoretical backing of a lately developed theoretical model by Cooper-Thomas and Anderson (2006). Their model comprised of five areas that they presented as domains that could define organisational socialisation effectiveness. Further, in the model, training relates to the "task, role, and performance" domain; co- worker support relates to the "co-worker, social, and group" dimension; understanding covered by "history, goals, and vales, and organisation" areas as well as their "politics" area; and future forecasts are matched with the "future prospects" dimension. (Taormina, 1997). Furthermore, Mitus (2006) referred Taormina (1994) among other eminent scholars (Anakwe \& Greenhaus, 1999; Holton, 1996) for identifying related types of socialisation content that employees learn after entering into the organisation. This highlights the collaboration visible between these models and acceptance of the Taormina (1994)'s theoretical content by other eminent scholars. The four domains of Taormina (1994)'s model are discussed in detail below.

\subsection{Training Domain}

Training is recognized as major people handling which enables to gain competitive edge for an organisation in the market place (Schuler \& MacMillan, 1984). According to Taormina (1997, p. 30), "this first domain could be labelled as the development of job-related skills and 
abilities, but the more concise term of 'Training' is used". According to Armstrong (2006), training is the application of structure and cited instructions in order to facilitate learning and knowledge dissemination. Accordingly, training is conceptualized as the action, procedure or technique by which one would obtains any sort of practical ability or skill required to perform a particular job in an organisation (Taormina, 1997). Based on the definitions given, it could be understood that training is the main organisational learning process to facilitate development of internal employees.

Literature identifies that training can be given in a formal manner or in an informal manner. Here, formal training is identified as any form of planned (e.g. workshop) sequence of instructions (such as functional job training, corrective training, reskilling) organized by an organisation to develop employees' job talents, involving managerial or executive job skills (Taormina, 1997). Armstrong (2006) identifies that, training involves the use of planned procedures to communicate knowledge and enable employees to obtain required skills to perform their tasks and duties in a satisfactory manner. Organisations have numerous ways of providing formal training to their employees. Organisations can recruit employees and put them through various technical training courses owned and facilitated by different industries. Apart from that employees can be sent to other training institutions or recruit an external consultant to provide employees the required training within the organisation (Taormina, 1997). Organisations can employ different training techniques such as instruction, lecture, discussion, case study, role playing, simulation, group exercises, etc. to provide formal training for employees. But in order for training to be effective, attention must be given to the training content, techniques used as well as to the nature of the participants-their fit to the job, development requirements, prior experience, current levels of knowledge and job related skills and the extent of acceptance given by employees for what has been taught (Armstrong, 2006).

In identifying the logic for the inclusion of training as a domain in the socialisation process of the organisation, Taormina (2009) justifies that psychologists and sociologists have mentioned the value of training in order to make employees socialised with the organisation, society, etc. This notion has been clearly confirmed by Erikson (1963), by demonstrating that socialisation begins in early stages of a person's life and developing certain necessary social skills (e.g. personal hygiene) is necessary to social settings (i.e. the family, groups, etc.) and continues as a lifelong process. While some scholars (e.g. Schein, 1980) suggested that training cannot be considered as part of employee socialisation process (or needs to consider as a separate process) most scholars (Feldman 1989; Fisher 1986; Reichers, 1987; Wanous 1980) agreed that training be considered an essential part of organizational socialisation. Feldman (1989) further confirms this by notifying that, "Indeed, in many cases, training has gone beyond being part of the socialisation process and has become synonymous with it" ( $p$. 399). Hence based on these arguments, it could be noted that training needs to be reflected as part of employee socialisation (but not the only domain) while there are other factors which needs to be included to arrive at a complete awareness of socialisation process. It could also be argued that as most employees are exposed to training more than once in their careers, this should be conceptualized as a continuous process (Taormina, 1997). 
In analyzing whether given effective training results in favorable attitudes towards the organisation studies conducted by Caldwell, Chatman, and O'Reilly (1990) and Tannenbaum, Mathieu, Salas, and Cannon- Bowers (1991) should be given notice. Caldwell, Chatman, and O'Reilly (1990), in their study identified a significant positive association between management training and employee commitment. Also, Tannenbaum, Mathieu, Salas, and Cannon- Bowers (1991) tested training fulfillment in the socialisation of army apprentices and found out that it was positively related to post-training organisational commitment, training motivation, and self-efficacy. However, Van Maanen (1975) in his study did not find any strong relationship betwwen training and employee outcomes. On contrary, Nordhaug (1989) found that mature workers who were given organizational training in their careers informed that through their training, they gained benefits such as greater inspiration, career advancement as well as physical and mental development. Based on these findings, several conclusions can be made that, if an employee feels that his/her training received is of greater value, his/her satisfaction with the job and supervisors, peers and subordinates, job itself would be greater. Further, good training would also result in high performance expertise, affective commitment as well as normative commitment towards the organisation. (Taormina, 1997).

\subsection{Understanding Domain}

Understanding can be defined as the "power or ability to apply concepts based on having a clear idea of the nature, significance, or explanation of something" (Taormina, 1997, p. 34). Understanding is an emotional process associated with a tangible or intangible object such as an individual, context, or a message through which a person is able to think and employ the concepts learned in order to get optimal use of that object (Bereiter, 2014). Regarding organisational socialisation, the term 'understanding' denotes specially to the magnitude to which a worker would completely grasps and applies information about his or her job, the organisation, its individuals and it's also its surrounding (Taormina, 1997).

According to Taormina (1994), understanding is a cognitive concept which can overlap with other domains discussed under socialisation. This is due to the fact that, understanding, thinking or intellection is something underlies in all facets of human activities, including organisational behaviour. Hence, it is persistent all over socialisation as employees need to think, understand what they are engaged in throughout their work span. However, Taormina, (1997) also stated that even though it is difficult to recognize understanding as a separate dimension due to its overlapping nature, this would allow HR practitioners to study and apply related concepts constructively to enhance validity of organisational socialisation programmes. The understanding domain incorporates several factors which would provide greater insights in understanding this concept intensely. For example, Louis (1980) used the term 'understanding' when identifying job role specific learning and culture learning as newcomer learning arenas under organisational socialisation having two basic kinds of content.

Apart from these there are many cognitive factors under different designations considered in identifying this concept. Some of these include: role clarity, reality shock (Buchanan, 1974); 
role definition, adjustment to group norms and values (Feldman, 1981); technical, social, referent, feedback and cultural information acquisition (Morrison, 1993); task, role, group and organisation learning (Ostroff \& Kozlowski, 1992); accepting organisational reality, developing one's role and identity and interpreting the reward system (Schein, 1978 as cited in Taormina, 1997). Apart from these, Chao et al. (1994) in his study has acknowledged four content areas of organisational socialisation which do not overlap with role, but which are also components of the understanding domain, namely: organisational goals and values, politics, language and history; which employees must gain through understanding.

Taormina (1994) identifies this as an essential component which needs special attention in order to execute assigned tasks effectively taking complete advantage of organisational socialisation. Though, other scholars have not used the term 'understanding' specifically in their organisational socialisation studies, it exist as other terminologies as essential part of organisational socialisation process. For instance, frequent definitions of organizational socialisation involve learning which has been emphasised in the studies of Van Maanen (1976 as cited in Taormina, 1997), Van Maanen and Schein (1979) while Wanous (1980) mentions about acquiring knowledge about an organisation (Taormina, 1997) which are the concepts related to understanding. Furthermore, Van Maanen and Schein (1979) employed the concept of understanding directly and openly in the discussions of underlying theories in organizational socialisation. However, Wanous (1980) stressed it as an implied objective of one of his socialisation tactics. Moreover, based on the studies of scholars such as Jones (1983); Louis (1980); Morrison (1993); Ostroff and Kozlowski (1992), it could be argued that the concept of understanding can be visible in every employee behaviour, without which employee cannot seek and internalise information about their jobs, roles, co-workers, organisation's goals, values, culture, etc. (Taormina, 1997). This highlights the fact that without understanding, organisation cannot function effectively.

Like the training domain, Taormina (1997) had taken greater effort to explain continuous process nature of understanding. It was justified depending on findings of Erikson (1963), where socialisation is specified as a life-long process. This perspective has been taken into consideration by Van Maanen (1976) where he indicates that understanding to be part of the overall life-long process of socialisation. Morrison and Hock (1986, p. 255) presented a considerable argument for understanding as a continuous process: "Experiences at work provide continuous opportunities for feedback about past, present, and future performance. The work itself is a constant source of such feedback, as are subordinates, peers, superiors, and other occupants of the various role sets". Further to this, Chao et al. (1994) was able to identify understanding as a continuous process in his study. In Feldman's (1981) model also understanding is given recognition in three stages and visible through the proposed process variables. Based on these findings, understanding can be perceived as a continuous lifelong process in employees' organisational tenure. When identifying the relationship of understanding with the concepts of commitment and job satisfaction, Taormina (1997) state that, there should be a moderate positive correlation with these concepts during short tenure periods and high positive association during long tenure period of employees which might range to five or more years. This is due to the fact that, newcomers tend to be starting to 
understand both positive and negative aspects of the organisation and organisation and might be in doubt whether to continue or discontinue their employment in the short run which would be due to less understanding. On contrast, employees with long tenures have a good understanding of the organisation, its culture, goals, etc enabling them to make decision $\mathrm{s}$ regarding staying or leaving the organisation (Taormina, 1997). Therefore, employees who are satisfied with the organisation would remain in the organisation for a longer time period. This is verified by Ostroff and Kozlowski (1992), found that employees with greater knowledge about organisational dimensions were more contented, devoted, and attuned to the organizational setup. Morrison (1993) also argued that if an employee understands his job and role in the organisation, this should have a positive impact on socialisation.

Nevertheless, it should be noted that, these studies examined only information seeking, but not understanding. Hence, Taormina (1997) proposed that, understanding might have significant correlations with involvement with the job, satisfaction with the duties of the job and the supervisors, co-workers, promotional opportunities as well as overall job as well. Understanding might also affect the employee attitudes regarding the language they use, history, politics, affective and normative commitment and organizational tenure as well. Taormina (1994) stated that by combining two dimensions of training and understanding can be viewed as 'orientation' as these involve a simultaneous process of learning and understanding. Hence, it can noted that from this perspective employee orientation becomes just a part of organisational socialisation.

\subsection{Co-worker Support}

Co-worker support is another critical component of organisational socialisation, which had been studied by many theorist such as Feldman (1981), Fisher (1986) and Reichers (1987). According to Zhou \& George (2001), co-worker support involves supporting your peers and subordinates when managing day to day tasks by sharing job related information, knowledge, expertise as well as the motivation and guidance needed in executing the assigned tasks. Employees might also consider acquiring job related know-how and proficiency from co-workers with the aim of learning novel ways of doing things (Perry-Smith, 2006). Langford, Bowsher, Maloney, and Lillis (1997) identified co-worker support as social support given by co-workers to other employees in the organisation. Langford et al. (1997) further recognised that, social support can be provided in terms of emotional support (concerned, understanding, faith), instrumental support (providing physical aid or goods), informational support helping resolving issues), and appraisal support (sharing self-evaluation). Whereas, Taormina (1997, p. 37) defined co-worker support with the same ideology as "emotional, moral or instrumental sustenance which is provided without financial compensation by other employees in the organisation in which one works with the objective of alleviating anxiety, fear or doubt". He further detailed the definition and identified the three components included as emotional and moral support which describes the verbal and behavioural encouragement/comfort (e.g. Encouragement for career advancement, hugs if permitted), Instrumental social support refers to the providing of physical support (e.g. lending necessary equipment). 
According to Taormina (1997), previous models on organisational socialisation identified it as a learning process and co-workers as guiding partners (e.g. teaching, values, etc.). But the current study differentiates by specifying co-worker support as manly relating to the provision of mental support for the employees and extricates it from teaching or training. To identify as co-worker support, all the caring activities must be provided free of charge; which would be otherwise considered as professional social service such as counselling services provided to employees. When identifying the reason for including co-worker support as a domain in the organisational socialisation, it could be seen that, even from the times of Maslow (1943) need for positive social relationships with others considered as a key element in employee satisfaction. "It could also be argued that, social support from co-workers should be included as a domain because of the undesirable consequences of what happens when social support is withheld" (Taormina, 1997, p. 39). If the employees do not get the social support expected from co-workers, employees might get isolated and would lead from ineffectiveness to resignation from the work place.

Van Maanen and Schein (1979), in his organisational socialisation model acknowledged that, when employees are in an organisational transition phase which might lead to anxiety producing situations require the support and guidance from colleagues and other associates. This highlights the fact that one's co-worker should be helping the employee to overcome the stressful situations which is a part of the social support required from the co-worker. The study conducted by Seers, McGee, Serey, and Graen (1983) found a relationship between coworker social support and job stress which aimed to identify whether social support acts more as a shield against stress or a means of coping with stress. These facts stress that while job stress can be viewed as an impediment to socialisation, co-worker support would act as a shield against it facilitating better socialisation. Facilitating this idea, Staw, Sutton and Pelled (1994), in their conceptual model related emotions at work and empahasised that favourable emotions are correlated with both supportive social context and greater achievement at office. The studies conducted by many scholars (e.g. Fisher, 1986; Feldman, 1981) have also identified the significance of reception of emotional and social support from peers and confirm the previously mentioned ideology to include co-worker support as a domain of organisational socialisation. Reichers (1987) also contributed in convincing this rationale stating that interactions between the newcomers and the experienced employees will act as the primary source of socialisation in the organisation.

The significance of reception of co-worker support is also identified in two recently-designed organisational socialisation measurement scales developed by Chao et al (1994) and Taormina, (1994). Further, Taormina (1997) presented a rational ideology to depict co-worker support as a continuous process. In his model, stated that, in order to illustrate this concept as an ongoing process, it is required to justify that it is essential for the employee to receive co-worker support throughout his/her tenure in the organisation. Taormina (1997)'s assumption is that most of the newly recruited employees might not be familiar with anyone in the organisation in their very first day at work. There can be exceptions where employees join in through personal contacts (In those instances initial support might be higher than expected but still might be low). Hence initial co-worker support might be of least value. Due 
to this issue, the entry level of co- worker support is expected to be at a lower rate. However, within a few weeks, employee might develop personal relationships with other co-workers which would increase the level of support received from them. However, in the long run support in order to establish themselves in the organisation, greater support from peers is required. In addition, there are many implications of co-worker support on human resource management practices which can be identified through different studies. Haines, Hurlbert, and Zimmer (1991) hypothesised that social support is significant in reducing employee stress levels. Researchers illustrated that, high levels of stressors would lead to produce strain in employees who are receiving low amounts of social support. Johnson and Hall (1988) further confirms this ideology stating that, employees who have to meet greter expectations in work, having low social support and low job control tend to have more health issues such as cardiac disease than those with high work demands but high social support. Klusmann, Kunter, Trautwein, Ludtke, and Baumert (2008) reported from a cross sectional study of teachers that social support was negatively related to emotional exhaustion. Van Vegchel, Jonge, Soderfeldt, Dormann, and Schaufeli (2004) also found that social support had a significant negative correlation with burnout measured one year later. These findings confirm that, co- worker support is an essential to alleviate emotional breakdowns of employees and to enhance their productivity. Co-worker support has also linked with innovative behaviour of employees. According to Perry-Smith (2006), employees can absorb job related knowledge from supportive peers which allows them to explore novel ways of doing things through open discussions and relations. Based on these findings it could be perceived that high levels of co-worker support can be positively correlates with the concepts of satisfaction, job performance, job involvement, affective, normative commitment, tenure and innovative behaviour. On the contrary, low levels of co-worker support has been correlated with turnover to intention and burnout.

\subsection{Future Prospects Domain}

Taormina (1997, p. 40) defined future prospects as "extent to which an employee anticipates having a rewarding career within his or her employing organisation". Buchanan (1974) stated that, this related to the acceptance of employees regarding the organization's procedure in relation to continuous future employment and the rewards expected. Hence, it could be noted that employees' main expectations in providing their effort to organisations are the long term job security as well as the internal and external benefits/rewards available for the future employment. Further, Taormina (1997) argued that there are numerous aspects of the job which can make one's employment an awarding one. These might include employee attitudes regarding probability of retention, current salary and future salary advancements, upcoming job assignments, career advancements, rewards, benefits, appreciation, etc. Hence, employees' perceptions regarding these rewards (whether the rewards/future prospects available are satisfactory or not) would determine their decisions to remain or resign from the work place (Reichers, 1987).

The argument Taormina (1997) brought in to rationalise the inclusion of future prospects as an essential element in the organisational socialisation is that; rewards are something expected by employees while it composes as a mechanism which creates the acceptance of 
employees to adjust to the ways of the organisation. Buchanan (1974) stated that employees are concerned whether the organisation is capable of adequately satisfying their need for achievements, which is another aspect of future prospects dimension. "Later in Buchanan's model (the second through fourth year of work) the employee is more concerned with such things as salary increments, promotions, etc., Buchanan regards these as reinforcements" (Taormina, 1997, p. 41). This highlights the fact that expected rewards as well as meaningful projects are an aspect of the future prospects domain. McClelland's (1961) research, also indicated that need for achievement may be regarded as an application of Maslow's theory of needs (especially the higher-order needs). He further mentions that, degree of need for achievement differs from one employee to another. If their anticipated job situations not achieved (e.g. not getting promotions on time or other colleagues getting promotions over oneself) they would be de motivated which would ultimately lead to resignations implying an unfavourable socialisation. Hence, this identifies the requirement to assess the individual employee opinions of their expectation in future (e.g., recognition, promotion). Fisher (1986) in her study on organisational socialisation observed that Van Maanen's (1976) assessment on socialisation was aimed at identifying the expectations of newcomers and their expected valence of rewards. Toffler (1981 as cited by Fisher, 1986) indicated that if the employees' expectations are unmet, would result in feelings of disappointment. Hence, it could be argued that if to keep employees within organisation for the long term, provision of a rewarding environment which supports their careers must be met. As a major objective of proper socialisation of employees is to keep them within having a proper rewarding structure (future prospects) is of greater importance.

In highlighting the effects and correlations between future prospects and HRM concepts, Taormina (1997) argues that, rewards would act as a motivator for look for future advancements. Hence, an association can be assumed between the availability of rewards, future prospects, and variables such as commitment or satisfaction. That is, if employee receives greater rewards and recognition (future prospects), would result in high commitment and job satisfaction. This was verified by Schwarzwald, Koslowsky, and Shalit (1992) who found that promoting employees result in greater levels of commitment. Further, Caldwell et al. (1990) also mentioned that, if the organisation is having a stronger reward system (not just promotions), would lead to greater commitment and opportunities for promotion would also result in greater job satisfaction. "Research evidence shows that when employees perceive they have little chance of success in their organisation, the result is poor socialisation, e.g. failure to get a promotion led to feelings of inequity and a decrease in commitment, and/or an increase in absenteeism" (Schwarzwald et al., 1992, p. 511) "or actual separation" (e.g. resignation) "from the organisation" (Kirschenbaum \& Weisberg 1990). Hence, based on the above finding, it could be noted that, employee future prospects are positively associated with job involvement, job performance, employee satisfaction with the job, supervisors, salary and the job itself as well. Future prospects are also associated with the three commitment forms of affective, continuance and normative and organizational tenure as well.

\section{3) Factors affecting Organisational Socialisation}

Under interactionist perspective (identification of not just situational factors but also 
individual factors), Reichers (1987) with reference to other socialisation theorist has identified several individual and situational factors which affect organisational socialisation, specially the factors affecting newcomers. These three individual variables identified below are the significant contributors to active behaviour in the newcomer perspective as they provide both drive and the ability to seek out interactions with others (Reichers, 1987). They are the field dependence (Witkin and Goodenough, 1977), tolerance of ambiguity (Budner, 1962), and need for affiliation (McClelland, 1961) or relatedness needs (Alderfer, 1969) of employees.

1. Field dependence provides employees with both the motivation (reliance upon the field as a referent) and the ability (interactive skills) to initiate the interactions that would enable employees to adapt to the organisational context.

2. Tolerance of ambiguity might become frequently indefinite regarding their novelty, complexity and seemingly contradictory nature. If the employees became intolerance of ambiguous situations, might jump into conclusions inhibiting the socialisation process.

3. Need for affiliation or relatedness needs. If the employees are longing for social relationships (due to high unmet affiliation needs), would take the opportunity to fulfil those through interactions with other employees in the work place.

Through these affiliations (e.g., having lunch with co-workers, going on tea breaks with others, casual grapevine, etc.) employees also get the advantage of exchanging information that would facilitate them to settle in the organisation (Reichers, 1987). Then, when identifying the situational factors which affect organisational socialisation, Reichers (1987) suggest that from the newcomers' perspective, other people in the work setting are elements of the situation. "Specifically, co-workers, supervisors, subordinates, clients, and/or customers act as agents of socialisation through which newcomers learn their appropriate work roles, engage in sense-making activities, and establish situational identity"(Reichers, 1987, p. 285). The argument that is brought in by Reichers (1987) is that, "Insiders" or the current employees of the organisation play a major role in adjusting new employees to the organisational context. If they act according to the individual variables mentioned above from an insider's perspective, higher interactions would result. Apart from that, formal orientation programs, on-the-job training, early performance evaluation, and/or formal mentoring or coaching relationships further demand collaboration between newcomers and existing employees.

However, Saks and Ashforth (1997) identified and summarised a variety of individual difference variables as predictors of socialisation outcomes. Self-efficacy is one of the most prominent individual difference variables to be discussed in socialisation research. (Saks \& Ashforth, 1997). According to Ashforth and Saks (1995) "newcomers' motives may be aroused by situation- specific and life-stage factors rather than stable, generalised, and salient desires. For example, a desire for feedback may be evoked by role ambiguity and the co-occurrence of other destabilizing transitions, such as a geographical relocation". Hence, motivation would also impact employee socialisation process. Previous work experiences of employees play a major role in socialisation process as those through which the employees 
make sense, identify similarities and contrasts of the current work situation (Louis, 1980). Hence, previous experiences would facilitate rapid socialisation. However, Meglino, Denisi and Ravlin (1993) in their study presented a contrasting viewpoint stating that, there is a higher tendency to find the negative aspects of the job by experienced applicants when the job previews were presented in the interviews.

In contrast, Bauer and Green (1994) found that previous research experience was positively related to the current level of research activities and research publications. Ashforth and Saks (1995) confirmed this finding reporting that previous work experience among recent business school graduates was positively related to role development. Thus, it is evident that, prior experience would facilitate employees to enhance their skills, level of confidence as well as the employees' innovative capability. Further, scholars such as Ashforth and Humphrey (1995) suggested that if there are any demographic differences (age, gender, and ethnicity) between the newcomers and the work group, there would be less social integration. Further, they postulate that, newcomers would be categorised as out-group at last at the beginning. However, on contrary, "individuals prefer to interact with in-group members, dissimilar newcomers may be denied instrumental and expressive social support, especially if their social identity has low status" (Jackson et al., 1993 as cited in Saks \& Ashforth, 1997, p. 253). Thus, it can be argued that which might damage the effective socialisation is not much to do with one's particular gender, race, ethnicity, or age per se, but the extent to which one is perceived to be different from others (Saks \& Ashforth, 1997).

\section{4) Effects of Organisational Socialisation}

This section is dedicated to identify the positive and negative effects of organisational socialisation. According to Bauer, Morrison, and Callister (1998), socialisation is of primary importance to the organisation as it ensures continuousness of central values, assisting newcomers with a framework on how to integrate and develop interrelationships with the work environment as well as other employees. Having an effective socialisation process, would result in employees gathering relevant knowledge about and how to adjust to new jobs, roles, work groups, and the culture of the organisation in order to become part of the organisational membership (Haueter et al., 2003; Saks, Uggerslev, \& Fassina, 2007).

It has also been argued that proper socialisation is most important at the entry level of the employees to the organisation as learning and adjustment issues are most important and problematic at this stage (Gregersen, 1993). Mitus (2006) also contributed to this ideology stating that, it is through socialisation that new employees gather diverse information about the organisation which may impact their level of commitment to the organisation. Acquisition of accurate information would also enable new employees to form a realistic job preview (role clarity) before entering in to the organisation (Ashforth, et al., 2007), to relieve emotional susceptibility (e.g. reducing job uncertainty (Bauer et al., 2007), anxiety, and stress), to strengthen social interactions between new employees and co-workers, and to facilitate learning and adjustment to a new working environment (Kennedy \& Berger, 1994). Theorists, Chao et al., (1994) and Feldman (1981) so acknowledged the importance of socialisation tactics as an information gathering process, but also stressed the importance of 
investigating the type and extent of information that new employees learn while being adapted to the organisation. Based on the above finings, it could be argued that better socialisation programmes would result in better adjustment of employees to the organisation through effective information gathering.

However, it needs to be noted that, socialisation is not just restricted to newcomers (Thomas \& Lankau, 2009). This is due to the frequent and extensive changes that are visible in the todays' dynamic work environment. This has transformed socialisation into a lifelong process encompassing individuals' entire careers as they continually need to refine their understanding of their job roles within and across organisations (Chao et al., 1994). Hence, it could be noted that, availability of effective socialisation processes would facilitate both the employees and the organisation to adapt to ongoing environmental changes which would result in continuous success for both.

Eminent scholars (e.g. Allen \& Mayer, 1990a; Feldman, 1981; Jones, 1986; Saks et al., 2007) have identified that, organisational socialisation is linked with many job related employee attitudes and behaviours. It has been frequently examined with socialisation outcomes such as intention to quit, job satisfaction, affective commitment and work roles, turnover intentions, job satisfaction, affective commitment, performance and role adjustment; work roles (Saks et al., 2007). Thomas and Lankau (2009) who explored the impact of leader- member exchange (LMX) and mentoring as sources of workplace social support established that, by demonstrating high LMX by employees' supervisors and other superiors will result in high socialisation and reduced job stress due to the reduction in mental tiredness. According to Manzoor and Naeem (2011), effective socialisation can have long lasting fruitful effects on employees by increasing person-organisation fit and person-job fit as well as employee commitment. The study conducted by Ashforth et al. (2007) shows that, institutionalised organisational socialisation tactics are positively related with job satisfaction. It was also found that intention to quit is promoted by having employee dissatisfaction regarding the work environment and its components. Hence, it is important to study effective socialisation as an antecedent to turnover (intentions) for better understanding and controlling turnover (Bigliardi, Prtroni, \& Dormio, 2005). Cooper-Thomas and Anderson (2006) also contribute to above ideology through their study.

In general terms, organisational socialisation programmes are designed to nurture employee adjustment. Bigliardi, Petroniand and Dormi (2005), in their study on engineers states that, providing training which is a primary domain of socialisation, for highly skilled employees (if they value training) would be more effective, thus, employees will be highly satisfied leading to greater organisational commitment. Further, understanding and support from supervisors and co-workers should also reduce mistakes and produce more effective engineers, giving them greater satisfaction. Feldman (1988) also suggested that greater understanding should lead to higher levels of organisational success, making engineers more committed to the company.

Ultimately, these positive interactions, understandings would result in greater organisational citizenship behaviour (Gundry, 1993 as cited in Bigliardi, Petroni, \& Dormi, 2005). 17 Hence, 
based on this comprehensive analysis of literature it could be concluded that organisational socialisation inherits more than employee orientation where it only reflects a minor aspect of employee socialisation where it runs for the lifetime.

\section{5) Summary}

The above comprehensive literature review assess whether organisational socialisation entails just employee orienting or whether it is a lifelong process where employees are benefited with a long term perspective. With this view, greater attention was given to the model developed by Taormina (2004) where he argued that socialisation is a continuous process which includes four major facets of training, understanding, co- worker support and future prospects.

\section{References}

Allen, N. J., \& Meyer, J. P. (1990a). The measurement and antecedents of affective, continuance and normative commitment to the organization. Journal of Occupational Psychology, 63(1), 1-18. https://doi.org/10.1111/j.2044-8325.1990.tb00506.x

Allen, N. J., \& Meyer, J. P. (1990b). Organizational socialization tactics: A longitudinal analysis of links to newcomers' commitment and role orientation. Academy of Management Journal, 33(4), 847-858. https://doi.org/10.2307/256294

Alderfer, C. P. (1969). An empirical test of a new theory of human needs. Organizational Behavior and Human Performance, 4(2), 142-175

Anakwe, U. P., \& Greenhaus, J. H. (1999). Effective socialization of employees: Socialization content perspective. Journal of Managerial Issues, 11, 315-329

Armstrong, M. (2006). A Handbook of Human Resource Management Practices (10 ed.). London: Kogan Page.

Ashforth, B., Sluss, D., \& Saks, A. (2007). Socialisation tactics, proactive behavior, and newcomer learning: Integrating socialisation models. Journal of Vocational Behavior, 70(3), 447-462. https://doi.org/10.1016/j.jvb.2007.02.001

Ashforth, B. E., Alan, M., \& Saks, A. M. (1995). Work-role transitions: A longitudinal examination of the Nicholson model. Journal of Occupational and Organizational Psychology, 68(2), 157-175.

Ashforth, B. E., \& Humphrey, R. H. (1995). Emotion in the workplace: A reappraisal. Human relations, 48(2), 97-125.

Bauer, T. N., Morrison, E. W., Callister, R. R., \& Ferris, G. R. (1998). Research in personnel and human resource management.

Bauer, T. N., Bodner, T., Erdogan, B., Truxillo, D. M., \& Tucker, J. S. (2007). Newcomer adjustment during organizational socialization: a meta-analytic review of antecedents, outcomes, and methods. Journal of applied psychology, 92(3), 707. https://doi.org/0.1037/0021-9010.92.3.707 
Bereiter, C. (2014). Principled practical knowledge: Not a bridge but a ladder. Journal of the Learning Sciences, 23(1), 4-17. https://doi.org/10.1080/10508406.2013.812533

Bigliardi, B., Petroni, A., \& Dormio, A. I. (2005). Organizational Socialization Career Aspirations and Turnover Intentions among Design Engineers. Leadership \& Organization Development Journal, 26(6), 424-441. https://doi.org/10.1108/01437730510617645

Buchanan, B. (1974). Building Organizational Commitment: The Socialization of Managers in Work Organizations. Administrative Science Quarterly, 19(4), 533-546.

Stanley Budner, N. Y. (1962). Intolerance of ambiguity as a personality variable. Journal of Personality, 30(1), 29-50. https://doi.org/10.1111/j.1467-6494.1962.tb02303.x

Caldwell, D. F., Chatman, J. A., \& O'Reilly, C. A. (1990). Building organizational commitment: A multifirm study. Journal of Occupational and Organizational Psychology, 63(3), 245-261.

Chao, G. T., O'Leary-Kelly, A. M., Wolf, S., Klein, H. J., \& Gardner, P. D. (1994). Organizational socialization: Its content and consequences. Journal of Applied Psychology, 79(5), 730-743.

Cooper-Thomas, H. D., \& Anderson, N. (2006). Organizational socialization: A new theoretical model and recommendations for future research and HRM practices in organizations. Journal of Managerial Psychology, 21(5), 492-516. https://doi.org/10.1108/02683940610673997

Erikson, E. (1963). Children and society. New York: Narton.

Feldman, D. (1981). The Multiple Socialization of Organization Members. The Academy of Management Review, 6(2), 309-318. Retrieved from http://www.jstor.org/stable/257888

Feldman, D. C. (1989) Socialization, resocialization and training: reshaping the research agenda. In I. Goldstein (ed.) Training and Development in Organizations (pp. 376-416). San Francisco: Jossey-Bass.

Filstad, C. (2011). Organizational commitment through organizational socialization tactics. Journal of Workplace Learning, 23(6), 376-390. https://doi.org/10.1108/13665621111154395

Gregersen, H. B. (1993). Multiple commitments at work and extra-role behavior during three stages of organizational tenure. Journal of Business Research, 26, 31-47. https://doi.org/10.1016/0148-2963(93)90041-M

Haines, V. A., Hurlbert, J. S., \& Zimmer, C. (1991). Occupational Stress, Social Support, and the Buffer Hypothesis. Work and Occupations, 18(1), 212-235.

Holton, E. F. (1996). The flawed four-level evaluation model. Human resource development quarterly, 7(1), 5-21. https://doi.org/10.1002/hrdq.3920070103

Johnson, J. V., \& Hall, E. M. (1988). Job Strain, Work Place Social Support and Cardiovascular Disease: A Cross Sectional Study of a Random Sample of the Swedish 
Working Population. American Journal of Public Health, 78, 1336-1342.

Kirschenbaum, A., \& Weisberg, J. (1990). Predicting worker turnover: An assessment of intent on actual separations. Human relations, 43(9), 829-847. https://doi.org/10.1177/001872679004300902

Klusmann, U., Kunter, M., Trautwein, U., Ludtke, O., \& Baumert, J. (2008). Engagement and Emotional Exhaustion in Teachers: Does the School Context Make a Difference? Applied Psychology: An International Review, 57, 127-151. https://doi.org/10.1111/j.14640597.2008.00358.x

Langford, C. P. H., Bowsher, J., Maloney, J. P., \& Lillis, P. P. (1997). Social support: a conceptual analysis. Journal of advanced nursing, 25(1), 95-100.

Louis, M. R. (1980). Suprise and Sensemaking: What Newcomers Experience Entering Unfamiliar Organizational Settings. Administrative Science Quarterly, 25, 226-251.

Manzoor, M., \& Naeem, H. (2011). Relationship of organization socialization with organizational commitment and turnover intention: Moderating role of perceived organizational support. Interdisciplinary Journal of Contemporary Research in Business, 3(8), 242- 261. Retrieved from http://www.journal-archieves13.webs.com

Maslow, A. H. (1943). A theory of human motivation. Psychological review, 50(4), 370.

McClelland, D. C. (1961). The achievement society. Princenton, NJ: Von Nostrand.

Meglino, B. M., Denisi, A. S., \& Ravlin, E. C. (1993). Effects of previous job exposure and subsequent job status on the functioning of a realistic job preview. Personnel Psychology, 46(4), 803-822. https://doi.org/10.1111/j.1744-6570.1993.tb01570.x

Mitus, J. (2006). Organizational socialization from a content perspective and its effect on the affective commitment of newly hired rehabilitation counsellors. Journal of Rehabilitation, 72(2), 12-20. https://doi.org/10.1108/00483481011064136

Morrison, E. (1993). Newcomer Information Seeking: Exploring Types, Modes, Sources, and Outcomes. The Academy of Management Journal, 36(3), 557-589. Retrieved from http://www.jstor.org/stable/256592

Nordhaug, O. (1989). Reward functions of personnel training. Human relations, 42(5), 373-388. https://doi.org/10.1177/001872678904200501

Ostroff, C., \& Kozlowski, S. W. (1992). Organizational socialization as a learning process: The role of information acquisition. Personnel Psychology, 45(4), 849-874. https://doi.org/10.1111/j.1744-6570.1992.tb00971.x

Perry-Smith, J. E. (2006). Social Yet Creative: The Role of Social Relationships in Facilitating Individual Creativity. Academy of Management Journal, 49, 85-101. https://doi.org/10.5465/AMJ.2006.20785503

Reichers, A. E. (1987). An Interactionist Perspective on Newcomer Socialization Rates. 
Academy of Management Review, 12, 278-287. https://doi.org/10.5465/AMR.1987.4307838

Saks, A. (1994). Moderating Effects of Self-Efficacy for the Relationship between Training Method and Anxiety and Stress Reactions of Newcomers. Journal of Organizational Behavior, 15, 639-654. https://doi.org/10.1002/job.4030150707

Saks, A. M., \& Ashforth, B. E. (1997). Organizational Socialisation: Making Sense of the Past and Present as a Prologue for the Future. Journal of Vocational Behavior, 51(2), 234-279. https://doi.org/10.1006/jvbe.1997.1614

Saks, A. M., \& Belcourt, M. (2006). An Investigation of Training Activities and Transfer of Training in Organizations. Human Resource Management, 45(4), 629-648. https://doi.org/10.1002/hrm.2013

Saks, A. M., Uggerslev, K. L., \& Fassina, N. E. (2007). Socialization tactics and newcomer adjustment: A meta-analytic review and test of a model. Journal of Vocational Behavior, 70(3), 413-446. https://doi.org/10.1016/j.jvb.2006.12.004

Schuler, R. S., \& MacMillan, I. C. (1984). Gaining Competitive Advantage through Human Resource Management Practices. Human Resource Management, 23(3), 241-255.

Seers, A., McGee, G., Serey, T., \& Graen, G. (1983). The Interaction of Job Stress and Social Support: A Strong Inference Investigation. The Academy of Management Journal, 26(2), 273-284. Retrieved from http://www.jstor.org/stable/255975

Schein, E.H. (1980). Organizational Psychology. Englewood Cliffs, NJ: Prentice-Hall.

Staw, B. M., Sutton, R. I., \& Pelled, L. H. (1994). Employee positive emotion and favorable outcomes at the workplace. Organization Science, 5(1), 51-71. https://doi.org/10.1287/orsc.5.1.51

Tannenbaum, S. I., Mathieu, J. E., Salas, E., \& Cannon-Bowers, J. A. (1991). Meeting trainees' expectations: The influence of training fulfillment on the development of commitment, self-efficacy, and motivation. Journal of applied psychology, 76(6), 759. https://doi.org/10.1037/00219010.76.6.759

Taormina, R. J. (1994). The organizational socialization inventory. International Journal of Selection and Assessment, 2(3), 133-145. https://doi.org/10.1111/j.1468-2389.1994.tb00134.x

Taormina, R. J. (1997). Organizational socialization: A multi domain, continuous process model. International Journal of Selection and Assessment, 5(1), 29-47. https://doi.org/10.1111/1468-2389.00043

Taormina, R. J. (2004). Convergent validation of two measures of organizational socialization. The International Journal of Human Resource Management, 15(1), 76-94. https://doi.org/10.1080/0958519032000157357

Taormina, R. J., \& Law, C. M. (2000). Approaches to Preventing Burnout: The Effects of Personal Stress Management and Organizational Socialization. Journal of Nursing Management, 8(2), 89-99. 


\section{Macrothink}

International Journal of Human Resource Studies

ISSN 2162-3058

2017, Vol. 7, No. 4

Taormina, R. J. (2009). Organizational socialization: the missing link between employee needs and organizational culture. Journal of Managerial Psychology, 24(7), 650-676. https://doi.org/10.1108/02683940910989039

Thomas, C. H., \& Lankau, M. J. (2009). Preventing burnout: The effects of LMX and mentoring on socialization, role stress, and burnout. Human Resource Management, 48(3), 417-432. https://doi.org/10.1002/hrm.20288

Van Maanen, J. (1975). Police socialization: A longitudinal examination of job attitudes in an urban police department. Administrative Science Quarterly, 207-228.

Van Maanen, J., \& Schein, E. H. (1979). Toward a Theory of Organizational Socialization. Research in Organizational Behavior, 209- 264.

Van Vegchel, N., de Jonge, J., Soderfeldt, M., Dormann, C., \& Schaufeli, W. B. (2004). Quantitative versus Emotional Demands among Swedish Human Service Employees: Moderating Effects of Job Control and Social Support. International Journal of Stress Management, 11(1), 21-40.

Wanous, J. P. (1980). The Entry of Newcomers Into Organizations. Michigan State University Witkin, H. A., \& Goodenough, D. R. (1977). Field dependence and interpersonal behavior. Psychological bulletin, 84(4), 661-689. https://doi.org/10.1037/0033-2909.84.4.661

Wu, L. F., \& Rocheleau, B. (2001). Formal versus Informal End User Training in Public and Private Sector Organizations. . Public Performance \& Management Review, 24(4), 312-321. https://doi.org/10.2307/3381221

Zhou, J., \& George, J. (2001). When Job Dissatisfaction Leads to Creativity: Encouraging the Expression of Voice. The Academy of Management Journal, 44(4), 682-696. Retrieved from http://www.jstor.org/stable/3069410

\section{Copyright Disclaimer}

Copyright for this article is retained by the author(s), with first publication rights granted to the journal.

This is an open-access article distributed under the terms and conditions of the Creative Commons Attribution license (http://creativecommons.org/licenses/by/4.0/). 